\title{
Comparison of pain levels in patients treated with 3 different orthodontic appliances - a randomized trial
}

\begin{abstract}
Rajasri Diddige ${ }^{1}$, Gunjan Negi ${ }^{1}$, Kanamarlapudi Venkata Sai Kiran ${ }^{2}$, Prasad Chitra ${ }^{1}$
\end{abstract}

1) Department of Orthodontics and Dentofacial Orthopedics, Army College of Dental Sciences, Secunderabad, Telangana, India

2) Department of Pedodontics and Preventive Dentistry, Narayana Dental College and Hospital, Nellore, Andhra Pradesh, India

DOI: $10.15386 / \mathrm{mpr}-1311$

Manuscript received: 18.02 .2019

Received in revised form: 28.05.2019

Accepted: 30.06 .2019

Address for correspondence:

prasadchitra@yahoo.co.uk

This work is licensed under a Creative Commons Attribution-NonCommercialNoDerivatives 4.0 International License

\begin{abstract}
Background and aims. To compare pain levels experienced during initial alignment with three different orthodontic appliance types and to correlate pain with male and female differences, if any.

Methods. A prospective, randomized 3-arm parallel trial allocated 36 adult orthodontic patients into three appliance groups: MBT 0.022" slot (Mini Twin, Ormco, Glendora, USA), self ligating 0.022" slot Damon 3MX (Ormco, Glendora, USA) and clear aligners (Smile align, Mumbai, India). The level of discomfort was assessed through a questionnaire based on the visual analogue scale at four hours, twenty four hours, third and seventh day after appliance placement.

Results. Patients treated with clear aligners reported less pain than patients treated with conventional and self ligating fixed appliances. Patients treated with MBT conventional appliances showed greater pain levels than Damon appliances. A significantly higher visual analogue scale score was observed at 24 hours and the least visual analogue scale scores on the seventh day post appliance placement.

Conclusion. During the first week of orthodontic treatment, patients treated with clear aligners reported lower pain than those treated with conventional and selfligating appliances.
\end{abstract}

Keywords: pain perception; visual analogue scale (VAS); orthodontic appliances

\section{Background and aims}

Pain is defined as "An unpleasant sensory and emotional experience associated with actual or potential tissue damage, or described in terms of such damage". by the International Association for the Study of Pain. In Greek, pain means penalty. In general, pain during orthodontic treatment is related to the duration and magnitude of force applied [1]. Reitan [2] suggested that light forces were less traumatic and biologically efficient during orthodontic tooth movement and discomfort might be associated with increased force levels. Frustman and Bernick [3] proposed that force application caused compression of the periodontal ligament, ischemia, inflammation and edema which in turn caused pain.

Discomfort and pain experienced during orthodontic treatment reduces compliance and is a reason to discontinue therapy [4]. The level of pain experienced during orthodontic treatment shows substantial individual variation due to psychological, environmental, psychosocial and emotional factors [5]. Several studies [6-12] have demonstrated that pain intensity rises between 4 to 24 hours after commencement of orthodontic treatment, lasts for 2 to 3 days with high intensity and gradually drops to baseline level by the $7^{\text {th }}$ day. Pain is generally measured indirectly using a visual analogue scale (VAS) which is a valid and reliable tool for assessing pain intensity. VAS is a horizontal 100 millimeter length line, anchored by word descriptors (least pain, severe pain) at each end, which provides good sensitivity and reproducibility $[7,13]$. 
Stewart et al. [14] and Sergl et al. [15] reported that fixed orthodontic appliances produced higher pain levels than removable appliances. Conventional and self ligating fixed appliances cause greater initial discomfort due to an increased inflammatory response and sensitized nociceptors. Some studies [5-7] have mentioned that there were no significant differences in pain experience with self ligating and conventional bracket systems, but in contrast, others reported [15-17] that patients treated with conventional appliances experienced higher levels of discomfort than self ligating appliances during initial alignment. Clear aligners were introduced into orthodontic practice in 1997 and since then, with improvements in technology and additional innovations, have become one of the most preferred orthodontic appliances by patients and orthodontists alike $[18,19]$.

Previous studies $[7,12,20]$ provided evidence of significant diurnal variability in orthodontic pain with maximum intensity in the evenings and nights and minimum in the afternoon. Females experienced higher diurnal variation than males. The concentrations of pain regulator mediators such as interleukins and Beta $(\beta)$ endorphins in plasma and the brain followed a circadian rhythm, and were predominantly responsible for diurnal variation in pain perception.

Brown and Moerenhout [21] illustrated that adolescents generally reported higher levels of pain in comparison to preadolescents and adults, due to their stage of psychological development. This finding is consistent with previous studies $[7,11,12]$ and provides evidence of age-dependent differences in pain perception where younger patients appear to perceive lesser pain than older patients. In contrast, Scott et al. [7] and Ngan et al. [10] demonstrated that there was no relation between age and pain perception. Some controversy exists regarding differences in pain perception between the sexes. Evidence showing no differences in perception $[7,9,11,13]$ and females experiencing greater levels of pain $[22,23]$ is available. Fixed orthodontic appliances have been associated with pain causation in almost all studies, but data for pain perception using clear aligners is less in comparison. Thus, it was found relevant to include 3 commonly used appliance treatment modalities, conventional fixed appliance mechanics using twin brackets, self ligating appliances and the newer mode of treatment with clear aligners which is commonly preferred by adults undergoing orthodontic treatment.

The aim of this study was to investigate differences in the degree of discomfort experienced during the initial phase of orthodontic therapy using 3 different appliance systems and further, to examine if pain perception was different between sexes and could be correlated.

\section{Methods}

An open ended randomized, prospective clinical trial design was adopted and utilized for selection of orthodontic subjects and subsequent treatment. The study was reviewed and approved by the Ethics Committee of the Army College of Dental Sciences, Secunderabad, India (ACDS/IEC/11/September 2018). Written informed consent was obtained from all participants. Sample size was estimated using GPower software v. 3.1.9.2. Considering the effect size to be measured at $55 \%$, power of the study at $80 \%$ and estimating a dropout rate of $5 \%$, a sample size of 36 (12 in each group) was recruited.

The criteria for subject inclusion was:

1. Subjects requiring non extraction fixed orthodontic therapy

2. Age ranging between $18-30 \mathrm{yrs}$

3. A full complement of teeth till 2nd molars

4. Class I malocclusion with Little's irregularity index between 3 to $5 \mathrm{~mm}$.

Subjects requiring extractions for orthodontic treatment, on medication or showing signs of periodontal disease were excluded. This was an explanatory, equivalence trial with parallel study design and a balanced allocation ratio of $1: 1: 1$. The participants were divided into three groups (Groups 1, 2 and 3) by simple randomization using a computer-generated random allocation sequence; 36 subjects requiring orthodontic therapy were equally divided into three groups. Each group (12 subjects) was further divided equally into two subgroups (6 males and 6 females). All procedures were performed by a single trained examiner and parameters were recorded by the same investigator.

Patients in Group 1 were treated using MBT 0.022" prescription fixed appliances (Mini Twin, Ormco, Glendora, USA), Group 2 were treated with 0.022 " prescription fixed appliances (Damon 3MX, Ormco, Glendora, USA) and Group 3 were treated using clear aligners (Smile Align, Mumbai, India). Both arches were bonded till the $2^{\text {nd }}$ molars in Groups 1 and 2 and 0.014" copper nitinol (CuNiTi) archwires were placed during the same session. For Group 1, the archwire was secured using stainless steel ligatures rather than elastomerics to minimize friction. A single set of clear aligners was given to Group 3 subjects in the aligner group and they were instructed to wear them for a minimum of 22 hours per day for a duration of two weeks.

Pain perception was assessed using a Health related quality of life(HRQoL) questionnaire [19] consisting of 9 questions (Figure 1).

The degree of pain was assessed using a Visual analogue scale (VAS) in the form of an unmarked $100 \mathrm{~mm}$ horizontal line. Patients were asked to fill the questionnaire and place a mark on the line that best matched the level of pain they experienced at 4 hours, 24 hours, day 3 and day 7 . The mark was measured using a millimeter scale to record pain intensity, and a value ranging from 0 to 100 $\mathrm{mm}$ was recorded at specified time intervals. 
1. Please mark an ' $\mathrm{X}$ ' on line below to indicate how severe discomfort has been at this point of

time.

no pain

severe pain

always repeatedly occasionally rarely never

2. Did you limit kinds of food you eat?

3. Do you have any trouble while chewing?

4. Do you have any trouble while speaking?

5. Were you happy with the looks of the appliance?

6. Did you use any medication for pain?

7. Were your teeth sensitive to cold?

8. Have you noticed any change in your sense of taste?

9. Was it difficult to sleep last night?

10. Has it been difficult to continue daily activities today?

Figure 1. Questionnaire.

\section{Statistical analysis}

Data analysis was carried out using the Statistical Package for Social Sciences [SPSS] for Windows, Version 22.0, 2013, Armonk, NY: IBM Corp. One - way analysis of variance (ANOVA) was done to compare between groups from 4 hours to day 7 . Independent $t$ test was performed to observe differences among male and female participants at the defined time intervals. The level of significance was set at $\mathrm{P}<0.05^{*}$.

\section{Results}

Thirty-six orthodontic patients in the study had ages ranging between 18 to 30 years with almost similar degree of teeth irregularity and were divided into 3 groups (Figure 2).

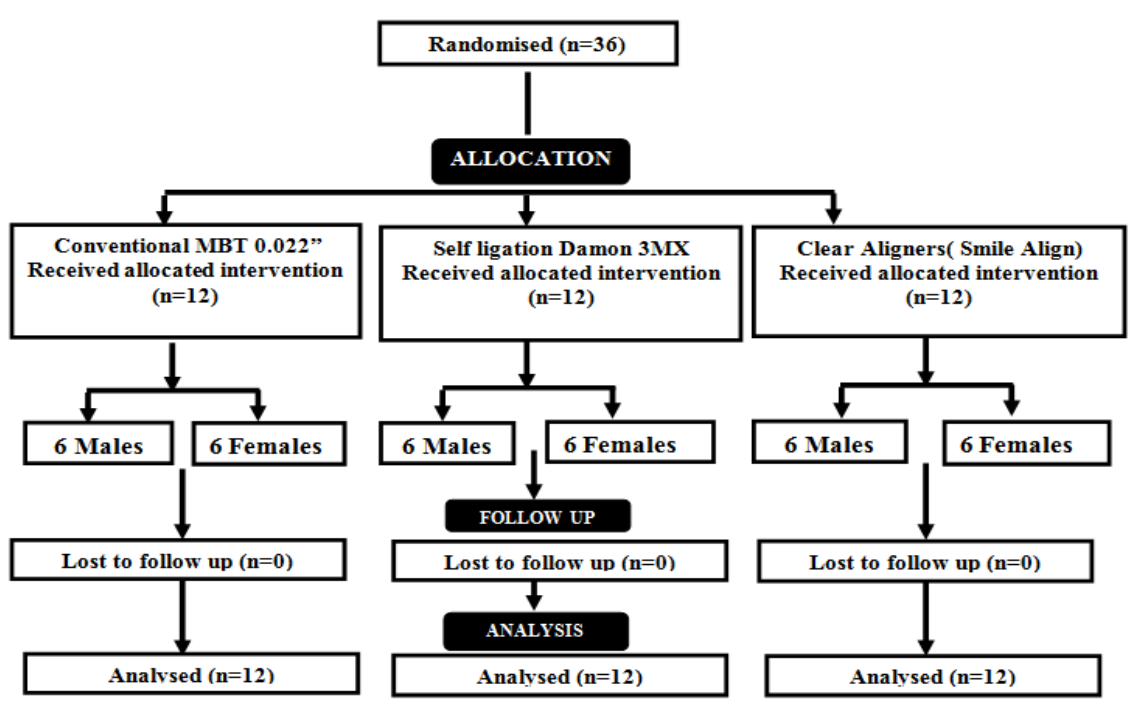

Figure 2. CONSORT Diagram of demographic representation. 


\section{Assessment of pain level}

During the first week of orthodontic treatment, pain levels increased significantly in all groups at 24 hours and then decreased by the $7^{\text {th }}$ day. Pain levels were consistently lower in the clear aligner group followed by the self ligating appliance group and conventional group. The differences were statistically significant $\left(\mathrm{p}=0.001^{*}\right)$ at four-time intervals (Table I, Figure 3).

Table I. Pain levels in the 3 tested groups.

\begin{tabular}{l|c|c|c|c|}
\hline Interval & Conventional & Self -ligation & Aligners & p value \\
\hline At 4 hrs & 5.17 & 3.76 & 2.67 & $0.001^{*}$ \\
24hrs & 5.53 & 3.82 & 2.72 & $0.001^{*}$ \\
Day 3 & 3.25 & 2.33 & 1.27 & $0.001^{*}$ \\
Day 7 & 2.49 & 1.65 & 1.20 & $0.001^{*}$
\end{tabular}

One Way ANOVA test; * indicates significance at $\mathrm{p} \leq 0.05$

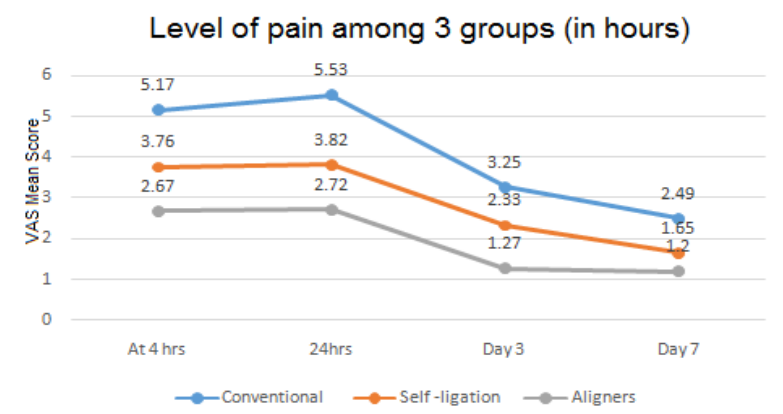

Figure 3. Pain levels in all 3 tested groups.

The first incidence of discomfort was reported 4 hours post appliance placement in all three groups. The level of discomfort reached its peak by 24 hours and gradually declined by day 3 . This pattern was observed in all 3 groups. Maximum intensity of pain was reported in patients treated using MBT conventional appliances followed by Damon $3 \mathrm{MX}$ self ligating appliances and clear aligners $(\mathrm{p}<0.001 *)$.
Female - Male differences in pain perception

Statistically significant differences were observed for pain perception between female and male subjects in conventionally treated group $1\left(\mathrm{P}=0.016^{*}\right)$, self ligation group $2\left(0.010^{*}\right)$ and the clear aligner group $3\left(0.007^{*}\right)$. During the first week of orthodontic treatment, females experienced higher intensity of pain than males in all 3 groups (Table II, III, IV).

Table II. Pain perception differences in females and males in the conventional MBT appliance group.

\begin{tabular}{l|c|c|c}
\hline Interval & Females & Males & p value \\
\hline At 4 hrs & 5.55 & 4.78 & $0.006^{*}$ \\
24hrs & 5.98 & 5.08 & $0.016^{*}$ \\
Day 3 & 3.67 & 2.83 & $0.005^{*}$ \\
Day 7 & 2.97 & 2.02 & $0.017^{*}$
\end{tabular}

Independent $\mathrm{t}$ test; * indicates significance at $\mathrm{p} \leq 0.05$

Table III. Pain perception differences in females and males in the Damon self ligation appliance group.

\begin{tabular}{l|c|c|c}
\hline Interval & Females & Males & p value \\
\hline At $4 \mathrm{hrs}$ & 3.78 & 3.31 & $0.008^{*}$ \\
24 hrs & 3.82 & 3.48 & $0.007^{*}$ \\
Day 3 & 2.82 & 1.85 & $0.003^{*}$ \\
Day 7 & 1.90 & 1.40 & $0.007^{*}$
\end{tabular}

Independent $\mathrm{t}$ test; * indicates significance at $\mathrm{p} \leq 0.05$

Table IV. Pain perception differences in females and males in the Clear aligner appliance group.

\begin{tabular}{l|c|c|c}
\hline Interval & Females & Males & p value \\
\hline At 4 hrs & 3.05 & 2.28 & $0.010^{*}$ \\
24hrs & 3.10 & 2.33 & $0.010^{*}$ \\
Day 3 & 1.57 & 1.17 & $0.007^{*}$ \\
Day 7 & 1.43 & 1.17 & $0.006^{*}$
\end{tabular}

Independent $t$ test; * indicates significance at $\mathrm{p} \leq 0.05$

Impact scores (Figures 4-7)

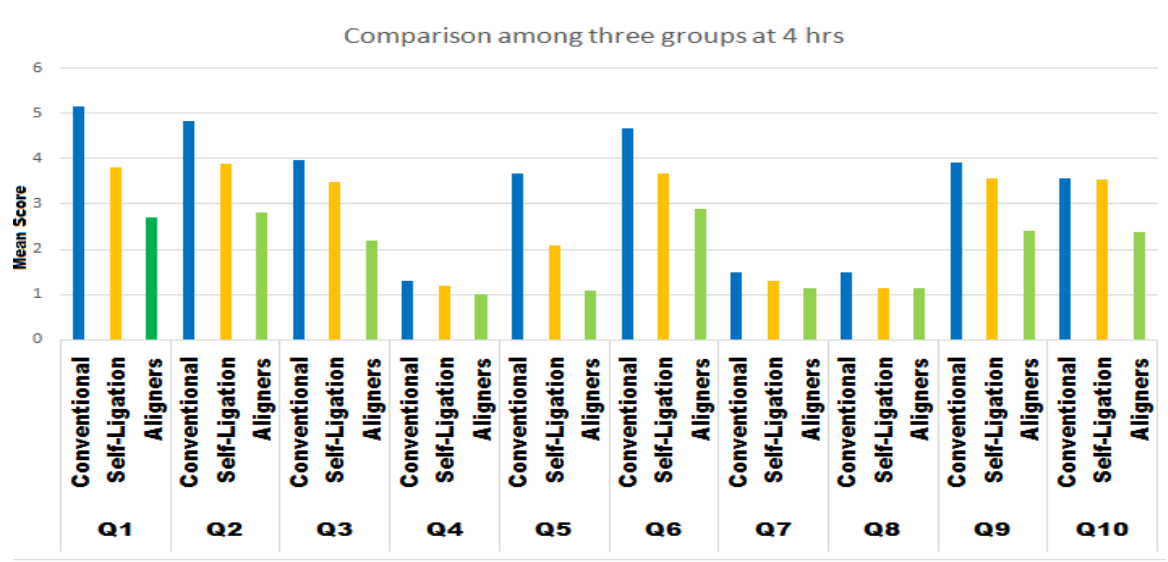

Figure 4. Pain levels in the 3 groups 4 hours post appliance placement. 
Comparison among three groups at $24 \mathrm{hrs}$

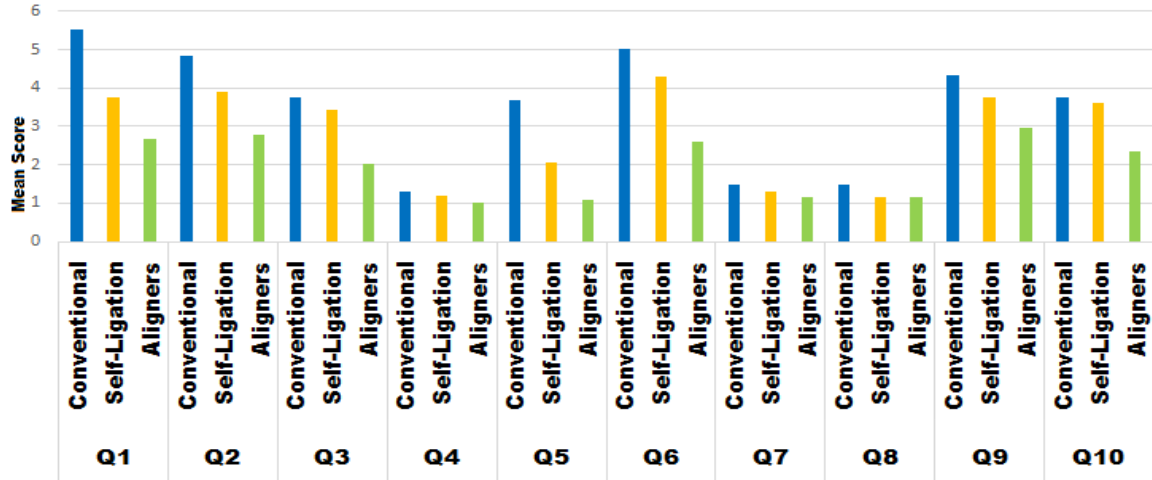

Figure 5. Pain levels in 3 groups 24 hours post appliance placement.

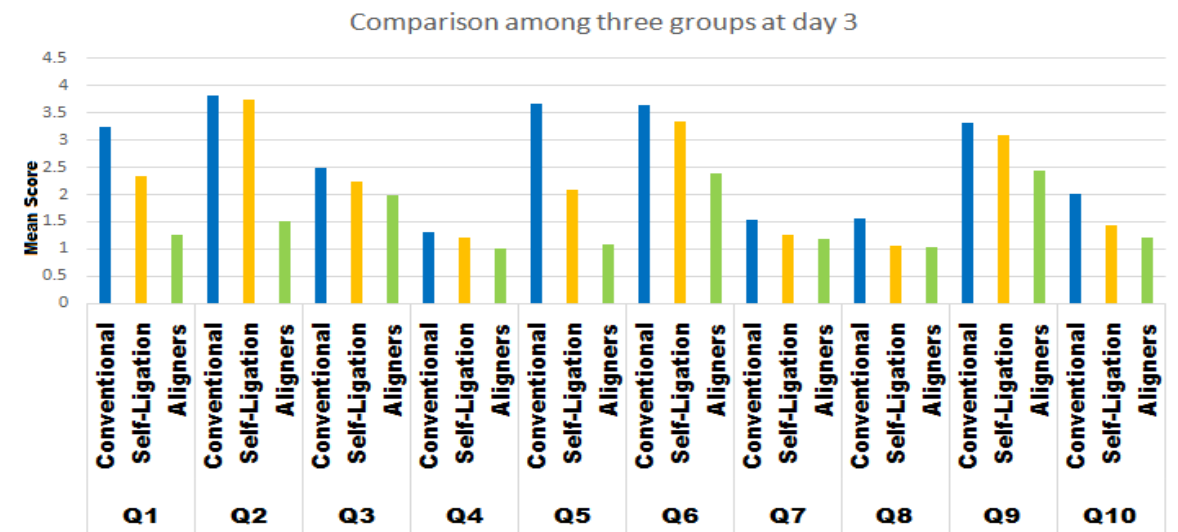

Figure 6. Pain levels in 3 groups 3 days post appliance placement

Comparison among three groups at day 7

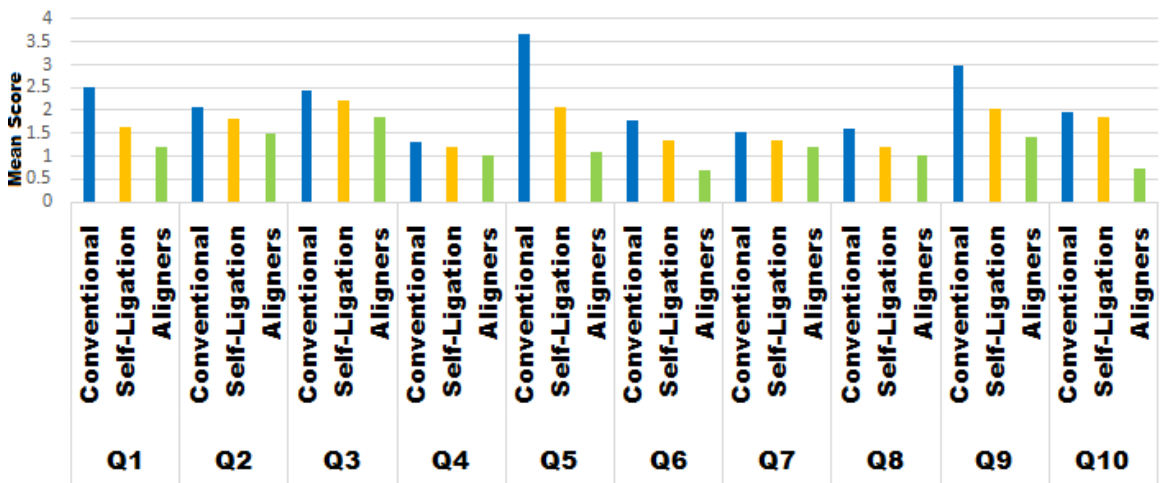

Figure 7. Pain levels in the 3 groups 7 days post appliance placement. 


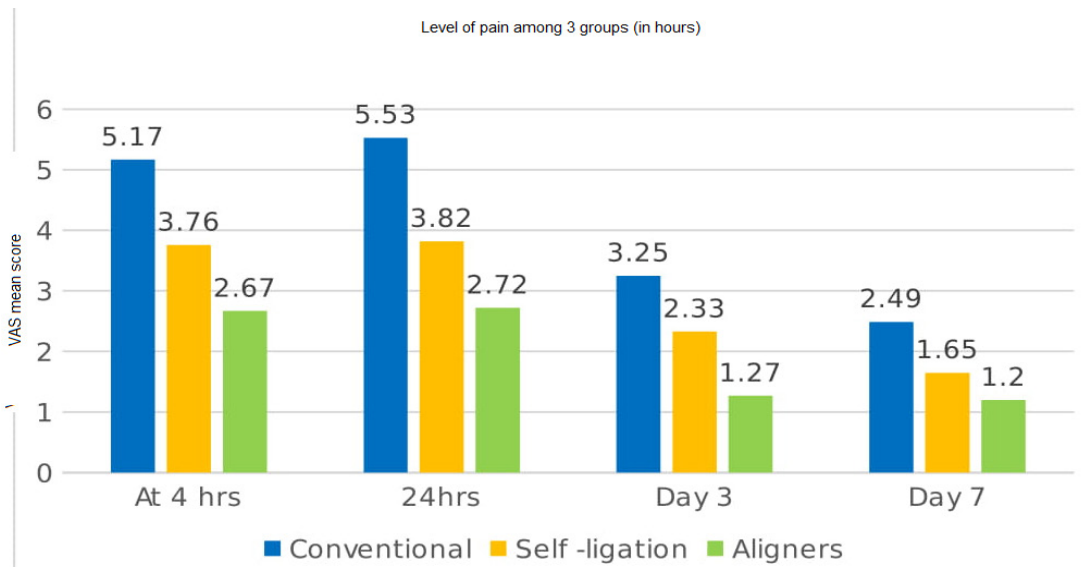

Figure 8. Pain comparisons among the 3 groups at tested time intervals.

\section{Eating disturbances}

Difficulties associated with eating, pain on chewing, teeth sensitive to cold and change in taste were assessed at four different intervals. Levels of disturbances in eating showed significant difference between all 3 groups $\left(p<0.001^{*}\right)$ at tested intervals. Maximum difficulties in eating were recorded for patients treated using conventional MBT appliances followed by self ligating appliances and clear aligners.

\section{Oral dysfunction}

Speech difficulty was assessed for all groups and no significant differences were observed. Speech in all groups improved by day $7(p<0.962)$.

\section{Psychosocial impact}

Patients in the clear aligner group reported maximum satisfaction with appliance aesthetics $\left(\mathrm{p}<0.001^{*}\right)$ as compared to conventional and self ligating groups. A significantly higher level of satisfaction was observed with patients wearing aligners.

\section{Analgesics}

Analgesic use showed significant differences between 3 groups $(p<0.001 *)$. Medication consumption was higher in the conventional group compared to self ligation or aligner groups and was statistically significant $\left(p<0.001^{*}\right)$. Analgesic intake reduced throughout the period of evaluation in all 3 groups.

\section{General activity}

To assess any changes in general activity, we examined sleep disturbances and difficulties in performing routine daily activities. There were no significant differences in all 3 groups $(p=0.298)$ at all four-time intervals. Levels of general activity dysfunction significantly decreased over time by day $7(\mathrm{p}<0.001 *)$.

\section{Discussion}

In the present study, 3 orthodontic appliances were compared for assessment of pain and overall impact scores during 7 days post orthodontic appliance placement. To make the study homogenous, a Little's irregularity index from mandibular canine to canine ranging between 3 to 5 $\mathrm{mm}$ was taken as criteria for subject inclusion [19].

Burstone [24] in 1962, identified immediate and delayed painful responses after orthodontic force application. The former was due to initial compression of the periodontal ligament (PDL) and the latter due to hyperalgesia of the PDL which caused increased PDL sensitivity to noxious agents such as histamine, prostaglandin $\mathrm{E}$ (PGE) and substance $\mathrm{P}$, which in turn lowers pain threshold.

In the present study, pain increased 4 hours after archwire placement in Groups 1 and 2, reached its peak by 24 hours and gradually reached baseline level by day 7. The results are similar to previous studies [7-13] and can be associated with the release of neuropeptides like Calcitonin Gene-Related Peptide (CGRP) and Substance P which evokes the secretion of pro inflammatory cytokines like Interleukin - 6 (IL-6), IL-1 $\beta$ and Tumor necrosis factor $(\mathrm{TNF}-\alpha)$. These lower the pain threshold by disruption of normal mechanisms associated with proprioception input from nerve endings in the PDL during the first two days after application of an orthodontic force [25].

Patients treated with self ligating appliances showed lower VAS scores than subjects treated using conventional appliances, which correlate with previous research findings $[16,17]$ and help illustrate that low friction associated with self ligating appliances generate less compression of the PDL preventing the cascade of events that are responsible for pain, like in conventional appliance systems.

Patients treated using clear aligners (removable) reported less pain than those treated with fixed (conventional and self ligation) appliances at all 4 intervals (Figure 8). The findings are concordant with previous 
studies $[14,15,19,26]$ and highlight the evidence that fixed appliances cause more discomfort than appliances that can be removed, during the initial phase of treatment. This is in part due to fixed appliances producing higher levels of tension, pressure, pain and sensitivity of teeth unlike removable appliances which have intermittent force application allowing tissue reorganization before compressive forces are reapplied.

Significant differences were found between groups regarding eating disturbances where the lowest levels of discomfort were in the clear aligner group and highest levels of discomfort in the conventional group. The results were consistent with the study done by Scheurer et al. [23] who reported that fixed appliances had more negative impact during eating than removable aligners because patients were instructed to eat without aligners [12,27]. In the present study, patients limited the food types they ate. Carter et al. [28] mentioned that they limited food consumption to minimize appliance breakages and decalcification. Patients treated with conventional brackets had a higher intensity of discomfort while chewing than at rest. Nicolay [29] associated it to the release of inflammatory mediators such as prostaglandins and substance $\mathrm{P}$ which sensitize nociceptors in the PDL after initiation of orthodontic forces which while chewing, compress previously sensitized nociceptors and cause more pain. During orthodontic treatment, some degree of tooth sensitivity and taste change may be observed while eating $[10,30]$.

A significantly higher level of satisfaction was observed with patients wearing clear aligners than fixed appliances. Oliver and Knapman [31] mentioned that the appearance of fixed appliances was the major discouraging factor during treatment. The aesthetics and removability of clear aligners accounted for functional and psychosocial differences between tested appliances [19].

No significant differences in oral dysfunction were noted between all 3 groups. Navarro et al. [32] and Khattaba et al. [33] stated that all intraoral orthodontic appliances produced speech difficulty because of tongue irritation with appliances that behave like foreign bodies within a system. It was observed that individuals showed no trouble while speaking, 30 days after appliance placement.

Significant differences in use of analgesics during the $1^{\text {st }}$ week of orthodontic treatment in 3 groups was observed. The pattern of analgesic use was correlated with level of pain intensity. A greater proportion of patients consumed analgesics during the first 2 days when pain intensity was higher in the conventional group than the other 2 groups. The results were consistent with other studies $[7,10,11,18,19]$.

No significant differences were found in levels of general activities in all 3 groups. Nijs et al. [34] mentioned that inflammatory cytokines like prostaglandin E2 potentially affected brain function and correlated it with increased sensitivity to painful stimuli and sleep restriction. Brown and Moerenhout, Scheurer and Oliver and Knapman reported that discomfort with orthodontic appliances affected daily life in general and it was most significant during the first two days [21,23,31].

In our study, females experienced a higher intensity of pain as compared to males at four different time intervals after appliance placement which were consistent with some studies $[12,18]$. Contrary to these results, several studies $[6,8,9,11]$ reported that there were no significant differences in pain perception between males and females. Factors underpinning sex differences in the experience of pain are multi factorial and complex including psychosocial and emotional influences. The influence of sex hormones represents pain related variability that impacts men and women differently. A substantial body of research indicates that women experience greater clinical pain and greater temporal pain with heightened sensitivity to experimentally induced pain as compared to men $[12,20,34,35]$.

Some study limitations were a small sample size and pain monitoring only at specifically defined time periods. A continuous monitoring system could help give better results. However, the study helped illustrate the clear differences in pain levels experienced by orthodontic subjects using 3 appliance systems at specific time periods. Selection of the optimum appliance for specific age groups and gender could help reduce the intensity of pain in most subjects.

\section{Conclusion}

Clear aligners caused the least discomfort and pain in subjects.

Self ligating Damon appliances caused lesser levels of discomfort as compared to conventional appliance systems, which should be kept in mind when planning orthodontic treatment in subjects with malocclusions not amenable to treatment with clear aligners.

Pain increased about 4 hours after placement of appliances, peaked at 24 hours and slowly reduced to baseline levels by the end of 7 days. The maximum use of analgesics was reported in the conventionally treated subject group which can be associated with tighter ligation and increased levels of friction.

Female subjects experienced greater levels of pain than males. This should be kept in mind while planning treatment for female subjects. Use of clear aligners and self ligating brackets in females could help in minimizing discomfort.

\section{References}

1. Treede RD. The International Association for the Study of Pain definition of pain: as valid in 2018 as in 1979, but in need of regularly updated footnotes. Pain Rep. 2018;3:e643.

2. Reitan K. Selecting forces in orthodontics. Trans Eur Orthod 
Soc. 1956;32:108-125.

3. Frustman L, Bernick S. Clinical considerations of the periodontium. Am J Orthod. 1972;61:138-155.

4. Bertl MH, Onodera K, Čelar AG. A prospective randomized split-mouth study on pain experience during chairside archwire manipulation in self-ligating and conventional brackets. Angle Orthod. 2013;83:292-297.

5. Rahman S, Spencer RJ, Littlewood SJ, O’Dywer L, Barber SK, Russell JS. A multicenter randomized controlled trial to compare a self-ligating bracket with a conventional bracket in a UK population: Part 2: Pain perception. Angle Orthod. 2016;86:149-156.

6. Fleming PS, Dibiase AT, Sarri G, Lee RT. Pain experience during initial alignment with a self-ligating and a conventional fixed orthodontic appliance system. A randomized controlled clinical trial. Angle Orthod. 2009;79:46-50.

7. Scott P, Sherriff M, Dibiase AT, Cobourne MT. Perception of discomfort during initial orthodontic tooth alignment using a self-ligating or conventional bracket system: a randomized clinical trial. Eur J Orthod. 2008;30:227-232.

8. Jones $\mathrm{M}, \mathrm{Chan} \mathrm{C}$. The pain and discomfort experienced during orthodontic treatment: a randomized controlled clinical trial of two initial aligning arch wires. Am J Orthod Dentofacial Orthop. 1992;102:373-381.

9. Jones ML. An investigation into the initial discomfort caused by placement of an archwire. Eur J Orthod. 1984;6:48-54.

10. Ngan P, Kess B, Wilson S. Perception of discomfort by patients undergoing orthodontic treatment. Am J Orthod Dentofacial Orthop. 1989;96:47-53.

11. Bergius M, Kiliaridis S, Berggren U. Pain in orthodontics. A review and discussion of the literature. J Orofac Orthop. 2000;61:125-137.

12. Fernandes LM, Ogaard B, Skoglund L. Pain and discomfort experienced after placement of a conventional or a superelastic NiTi aligning archwire. A randomized clinical trial. J Orofac Orthop. 1998;59:331-339.

13. Bijur PE, Silver W, Gallagher EJ. Reliability of the visual analog scale for measurement of acute pain. Acad Emerg Med. 2001;8:1153-1157.

14. Stewart FN, Kerr WJ, Taylor PJ. Appliance wear: the patient's point of view. Eur J Orthod. 1997;19:377-382.

15. Sergl HG, Klages U, Zentner A. Functional and social discomfort during orthodontic treatment--effects on compliance and prediction of patients' adaptation by personality variables. Eur J Orthod. 2000;22:307-315.

16. Pringle AM, Petrie A, Cunningham SJ, McKnight $M$. Prospective randomized clinical trial to compare pain levels associated with 2 orthodontic fixed bracket systems. Am J Orthod Dentofacial Orthop. 2009;136:160-167.

17. Miles PG, Weyant RJ, Rustveld L. A clinical trial of Damon 2 vs conventional twin brackets during initial alignment. Angle Orthod. 2006;76:480-485.

18. Tecco S, D'Attilio M, Tetè S, Festa F. Prevalence and type of pain during conventional and self-ligating orthodontic treatment. Eur J Orthod. 2009;31:380-384.

19. Miller KB, McGorray SP, Womack R, Quintero JC, Perelmuter $\mathrm{M}$, Gibson J, et al. A comparison of treatment impacts between
Invisalign aligner and fixed appliance therapy during the first week of treatment. Am J Orthod Dentofacial Orthop. 2007;131:302.e1-e9.

20. White DW, Julein KC, Jacob H, Campbell PM, Buschang PH. Discomfort associated with Invisalign and traditional brackets: A randomized, prospective trial. Angle Orthod. 2017;87:801-808.

21. Brown DF, Moerenhout RG. The pain experience and psychological adjustment to orthodontic treatment of preadolescents, adolescents, and adults. Am J Orthod Dentofacial Orthop. 1991;100:349-356.

22. Sandhu S, Leckie G. Diurnal Variation in orthodontic pain: Clinical implications and pharmacological management. Semin Orthod. 2018;24:217-224.

23. Scheurer PA, Firestone AR, Bürgin WB. Perception of pain as a result of orthodontic treatment with fixed appliances. Eur J Orthod. 1996;18:349-357.

24. Burstone CJ. Biomechanics of tooth movement .In: Krause BS, ed.Vistas in orthodontics. Philadelphia: Lea and Febiger, 1964: p. 197-213.

25. Batham P, Batham A, Kalia U, Nagar A, Jain S. Pathways of pain to pleasure in orthodontics: A review. Indian J Orthod Dentofacial Res. 2017;3:124-128.

26. Shalish M, Cooper-Kazaz R, Ivgi I, Canetti L, Tsur B, Bachar E, et al. Adult patients' adjustability to orthodontic appliances. Part I: a comparison between Labial, Lingual, and Invisalign ${ }^{\mathrm{TM}}$. Eur J Orthod. 2012;34:724-730.

27. Krishnan V. Orthodontic pain: from causes to management--a review. Eur J Orthod. 2007;29:170-179.

28. Carter LA, Geldenhuys M, Moynihan PJ, Slater DR, Exley CE, Rolland SL. The impact of orthodontic appliances on eating - young people's views and experiences. J Orthod. 2015;42:114-122.

29. Nicolay OF, Davidovitch Z, Shanfeld JL, Alley K. Substance $\mathrm{P}$ immunoreactivity in periodontal tissues during orthodontic tooth movement. Bone Miner. 1990;11:19-29.

30. Fujiyama K, Honjo T, Suzuki M, Matsuoka S, Deguchi T. Analysis of pain level in cases treated with Invisalign aligner: comparison with fixed edgewise appliance therapy. Prog Orthod. 2014;15:64.

31. Oliver RG, Knapman YM. Attitudes to orthodontic treatment. Br J Orthod. 1985;12:179-188.

32. Navarro PR, Assis GB, Souza LL, Macluf F E, Azenha CR, Tessitore A. Changes in oral functions in presence of fixed orthodontic appliances with features intraoral. Rev CEFAC. Cefac. 2013;15:1281-1290.

33. Khattab TZ, Farah H, Al-Sabbagh R, Hajeer MY, Haj-Hamed Y. Speech performance and oral impairments with lingual and labial orthodontic appliances in the first stage of fixed treatment: A randomized controlled trial. Angle Orthod. 2013;83:519-526.

34. Nijs J, Mairesse O, Neu D, Leysen L, Danneels L, Cagnie B, et al. Sleep Disturbances in Chronic Pain: Neurobiology, Assessment, and Treatment in Physical Therapist Practice. Phys Ther. 2018;98:325-335.

35. Bartley EJ, Fillingim RB. Sex differences in pain: a brief review of clinical and experimental findings. Br J Anaesth. 2013;111:52-58 